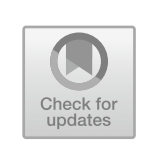

\title{
Co-constructing an Opportunity with a Community of Inquiry
}

\begin{abstract}
Entrepreneurs can learn about potential opportunities through social interactions with communities of inquiry. However, how do entrepreneurs build such communities, and how do they engage community members over time to develop their potential opportunities? Building on a recent study of eight new ventures and their communities of inquiry over nine months (Shepherd et al. in Journal of Business Venturing, 106033), this chapter presents a social model of opportunity development. The chapter explains how entrepreneurial teams that progress well toward market launch consist of varied specialists who openly engage their communities of inquiry. This open engagement leads such teams to gather diverse information, generate multiple alternatives (technology and market), and test conjectures about their potential opportunities through disconfirmation. In contrast, unsuccessful entrepreneurial teams rely on focused engagement with their communities of inquiry. This focused engagement leads these teams to gather specific information, generate a few related alternatives, and seek to confirm their opportunity conjectures. This chapter highlights new insights into entrepreneurial teams' engagement with communities of inquiry to explain opportunity development and, ultimately, new venture progress.
\end{abstract}

This chapter is based on Shepherd et al. (2020). The assertions that we make in this chapter are justified, cited, and referenced in Shepherd et al. (2020).

(C) The Author(s) 2021

D. A. Shepherd and H. Patzelt, Entrepreneurial Strategy, https://doi.org/10.1007/978-3-030-78935-0_2 
In the previous chapter, we focused on how individuals notice a change in the external environment that indicates a potential opportunity. This chapter focuses on the social environment and how it can help entrepreneurs develop potential opportunities. Indeed, the entrepreneurship literature has long established the importance of entrepreneurs learning through interactions with others. This social learning is fundamental to recognizing and pursuing potential opportunities. A community of inquiry is a body of interested parties who promote social learning to develop a potential opportunity. In other words, a community of inquiry is the group of potential stakeholders who provide feedback to an entrepreneur regarding the veracity of his or her potential opportunity. Members of such communities include potential customers, mentors, investors, and technological experts.

The social learning that entrepreneurs engage in by interacting with communities of inquiry produces information that reduces the uncertainty typically surrounding entrepreneurs' opportunity decisions and actions. In turn, entrepreneurs use this information gained from social interactions to update their current opportunity beliefs. As opportunity development progresses, entrepreneurs have different information demands that they can satisfy by changing the nature of their communities of inquiry. Entrepreneurs can change their communities of inquiry by, for example, forming new relationships and terminating relationships that are no longer useful.

Although prior research has highlighted the importance of entrepreneurs updating their opportunity beliefs based on information from their communities of inquiry, there is a gap in the literature on how entrepreneurs engage their communities of inquiry. Building knowledge on entrepreneurs' ongoing (and changing) interactions with their communities of inquiry (which also change over time) is critical to advancing our understanding of opportunity development.

First, as opportunity development represents a process, entrepreneurs face different tasks and resource requirements over time (Greve \& Salaff, 2003; Kazanjian, 1988). Entrepreneurs likely use their contacts and relationships to perform these tasks and satisfy these requirements as they arise. Given the importance of social learning to entrepreneurs for developing their potential opportunities, we can gain a great deal by investigating how entrepreneurs interact with communities of inquiry over time to refine their opportunities and make progress with the new ventures they create to exploit these opportunities. Second, actors' 
current knowledge shapes their search for new information (Dosi, 1982; McFadyen \& Cannella, 2004). The search for information and opportunity development can become mutually dependent. Therefore, understanding how entrepreneurs engage communities of inquiry can provide insights into opportunity development, and understanding how entrepreneurs develop potential opportunities can provide insights into entrepreneurs' community-of-inquiry engagement. Finally, the nature of opportunity development affects new venture progress and performance (Alvarez et al., 2015; Sarasvathy, 2001). Therefore, as we learn more about how entrepreneurs develop their opportunities, we can gain new insights into new venture progress.

Therefore, in this chapter, we ask (and hopefully address) the following question: how do entrepreneurs engage communities of inquiryto develop opportunities? We conducted a longitudinal inductive study of eight new ventures and their communities of inquiry over nine months (for specifics, see Shepherd et al., 2020) to address this research question. We offer a social model of opportunity development from this data-collection and analysis effort. We believe that this model makes three primary contributions to the entrepreneurship literature.

First, entrepreneurship research has investigated the social aspects of opportunity development by focusing on entrepreneurs' networks, social capital, and interactions with communities of inquiry (De Carolis \& Saparito, 2006; Hoang \& Antoncic, 2003). This chapter identifies entrepreneurs' different approaches to community engagement (open vs. focused) to explain how some entrepreneurs capture more value from communities of inquiry for opportunity development than other entrepreneurs.

Second, prior knowledge is critical for recognizing potential opportunities (Dencker et al., 2009; Grégoire et al., 2010). However, there are limitations to using prior knowledge to inform actions in an uncertain environment because it may not apply to that environment. In this chapter, we show how entrepreneurs' open engagement with their communities of inquiry when developing potential opportunities can overcome some of the limitations associated with using prior knowledge in uncertain environments. Thus, we extend theorizing on entrepreneurs' prior knowledge by highlighting a "social" learning approach to opportunity development.

Finally, previous research has indicated the importance of a community of inquiry for opportunity development (Autio et al., 2013; Shepherd, 
2015). This chapter highlights how proposing that entrepreneurs merely interact with communities of inquiry is insufficient for elucidating the complexity of the social-learning process. Rather, opportunity development depends on the type of interaction entrepreneurs' have with their communities of inquiry. Therefore, we help explain why and how entrepreneurs differ in the ways they gather information, generate alternatives, and test opportunity conjectures. Thus, the social model of opportunity development (Shepherd et al., 2020) advances our understanding of the changes to a potential opportunity for venture progress by detailing entrepreneurs' critical social interactions with a community of inquiry.

\section{COMMUNities OF INQUiRY AND OpPortunity DEVElopMent}

We often think of opportunities as coming fully packaged at a single point in time. For example, scholars have defined opportunities as "situations in which new goods, services, raw materials, markets, and organizational methods can be introduced through the formation of new means, ends, or means-ends relationships" (Eckhardt \& Shane, 2003, p. 336). However, to complement our understanding of opportunities at a point in time, more research is needed on the dynamic aspects by which opportunities advance toward highly developed opportunities as drivers of new venture progress. Therefore, we define opportunity development as a dynamic stream of ideas for a new product or service, which, when enacted, increase stakeholders' confidence in the viability of the focal potential opportunity. Potential opportunities develop as entrepreneurs generate new information through creative insights to probe an uncertain environment by interacting with members of a community of inquiry.

As potential opportunities are dynamic and uncertain, opportunity development is driven by entrepreneurs' conjectures about future possibilities. Specifically, entrepreneurs form beliefs about desired end states and preferred courses of action. These opportunity beliefs are futurefocused "mental images or 'theories' about the potential reward for a particular action versus the cost of that action" (Wood et al., 2014, p. 253). Opportunity beliefs draw on founders' knowledge, motivation, and external information and guide action by organizing knowledge. While prior knowledge is important in forming opportunity beliefs, we know little about how opportunity beliefs change over time. 
The small stream of research on reevaluations for opportunity development has focused on entrepreneurs' and other new venture members' learning. From this perspective, entrepreneurs' limited attention guides learning. Therefore, different attentional engagement modes explain differences in entrepreneurs' ability to notice, interpret, and use environmental signals to develop opportunity beliefs. Specifically, entrepreneurs engage in either top-down or bottom-up processes of allocating attention (see Chapter 1). Top-down information processing uses existing knowledge structures to direct attention to aspects of the environment that entrepreneurs expect to be relevant. Bottom-up processes rely on the environment's gestalt properties to enable entrepreneurs to identify patterns to make sense of the environment inductively. The choice of attentional mode influences how entrepreneurs notice and evaluate potential opportunities (see Chapter 1). However, to date, we know little about how entrepreneurs engage others to access and acquire further opportunity-related information. Filling this gap will advance our understanding of opportunity-development progress, yielding important implications for entrepreneurs, their stakeholders, and their ventures.

\section{Progress in Opportunity Development}

Our study (Shepherd et al., 2020) found that four of the eight ventures we studied had made substantial progress, while the others had made little progress. Progress in opportunity development refers to how the ventures' simple concepts that initially represented potential opportunities became more elaborate through improvements in the potential opportunities' fit with the internal and external environments. We used fictitious names starting with "P" to reflect this strong progress in opportunity development-Penn, Peppi, Philipinna, and Perahta. Illustrative of these ventures' progress, the coach of Peppi shared his assessment of the entrepreneurial team:

This is really a dream team. I think when a team understands product and customer development and is open to feedback, then it doesn't matter which solution or technology they started with. I don't know if there will be more changes to Peppi's product, but they'll be able to do them if necessary. (p. 8) 
One of Peppi's founders described how the team developed their opportunity:

Two pivots later, we're personally involved in interactions with customers every day and have actually learned how customers make decisions, what features they value [and] how much. That has brought our product to even another level. We originally emphasized collaboration but shifted toward knowledge management because we have learned that it gives us easier market access. Our users have made lots of request toward it ..., and it has landed us our first big paying client. (p. 8)

In contrast to Penn, Peppi, Philipinna, and Perahta, four ventures made only limited opportunity-development progress. We used names starting with "L" to denote their lack of progress-Lamar, Ludwig, Lorah, and Luete. Specifically, these ventures enacted very limited changes to their original ideas. For example, these unsuccessful ventures made only minimal changes to their prototypes over time. The entrepreneurs struggled to identify how they were going to try and improve their initial potential opportunities. Ultimately, these ventures did not make sufficient improvements to enable opportunity development. For example, the founder of Luete noted the following:

There might have been signs that it isn't going anywhere. The others kept saying let's try this too and let's do that again from scratch, and I said we don't have the resources but go ahead if you think that's the right way. But I zoned out because I was unhappy. But we actually finished the first prototype now, and it works mechanically and electronically... We just don't believe that the market is big enough anymore. So, we'll end it by publishing everything open source. (pp. 8-9)

These entrepreneurial teams realized quite late that there were some important questions about whether there would be sufficient demand for their proposed products. Lamar and Luete eventually realized that the prices customers were willing to pay were below production costs. As a result, Lamar and Lorah decided to pivot from the initial conceptualizations of their potential opportunities. In contrast, Ludwig and Luete terminated their projects (and the new ventures they created to exploit their potential opportunities) because of their limited progress. 


\section{Entrepreneurial Team Knowledge and Engaging a Community of Inquiry}

Entrepreneurial teams differ in how they approach learning about their potential opportunities. These differences help explain why some ventures experience substantial progress in opportunity development while others do not. Entrepreneurial teams' prior knowledge helps explain why entrepreneurial teams differ from other entrepreneurial teams in learning new information.

\section{Progress in Opportunity Development, Open Community Engagement, and Entrepreneurial Teams of Varied Specialists}

In our study (Shepherd et al., 2020), the entrepreneurial teams that progressed well in opportunity development recognized the importance of capturing unexpected information about their potential opportunities. Specifically, these teams included members who had specialized knowledge (market and technological) that was mostly different from the other team members' specialized knowledge. For example, Penn's mentor lauded that one founder "brings customer experience from the industry... while the other founder's technical skills position the team extremely well." Similarly, one of the founders for Perahta explained, "It's not like we are developing a product for customers and problems we only vaguely know something about. We're from this field." Indeed, each team had at least one member who had experienced the focal problem firsthand and had searched for a solution to it, and some were lead users of the new ventures' products and services. Lead users included a nurse in Penn, a service technician in Philipinna, and a PhD student in Perahta.

The heterogeneity in members' prior knowledge meant that these teams were open minded about who they interacted with and how those interactions might draw their attention to new, unexpected information about their potential opportunities. Because of the differences in the members' knowledge expertise, these entrepreneurial teams were aware of the limitations of any one source of prior knowledge. These entrepreneurial teams knew that despite their knowledge sources' diversity, there were things they did not know about their potential opportunities. This awareness of their knowledge limitations drove these teams to focus on collecting and interpreting unexpected information to facilitate their learning about their potential opportunities. Specifically, in the teams of varied specialists, each member learned from the other members 
that his or her own knowledge was not all encompassing. Thus, the team members realized that they could not solely rely on their own expectations about what was critical for opportunity development. These successful teams collectively engaged with their communities of inquiry to reveal information not covered by their prior knowledge. For example, a founder of Penn explained, "The nurses are our co-creators and real customers.... We have to listen to what they tell us they need the most, meaning the problems they have that have not been solved."

Therefore, because they were composed of diverse specialists, these teams approached their communities of inquiry with open engagement. By open community engagement, we mean that these entrepreneurial teams engaged their communities of inquiry to explore potentially surprising knowledge sources to inform their opportunity development. The Peppi coach noted how team members were "extremely open.... They don't decide themselves what they will do but let the customer decide. They just accept feedback on what could be critical and test it and go for what works best."

\section{Lacking Progress in Opportunity Development, Focused Community Engagement, and Entrepreneurial Teams of Generalists}

The ventures lacking progress in developing their potential opportunity had relatively homogenous entrepreneurial teams. That is, the team members had similar and somewhat general knowledge of technologies and markets. One of the entrepreneurs of Lamar believed that the team's general knowledge of technology and markets was a strength and that it was important that they focused on the team's strength. He stated, "Our strength lies in our innovativeness... We know what we want, and how we achieve it is a function of our potential."

While generalist knowledge is often considered an advantage in running a new venture, entrepreneurs should be "jacks-of-all-trades." When it comes to engaging communities of inquiry to develop their potential opportunities, these teams' general knowledge led them to pay little attention to the specific gaps in their prior knowledge. Therefore, they did not focus on how community members could fill their knowledge gaps with new and unexpected information. Indeed, the entrepreneurial teams of (relatively homogenous) generalists believed they covered the terrain's scope sufficiently to identify specific (expected) problems and acquired specialized information to address these problems. For example, a member of Lamar told us the following: "From our research, 
there's a huge unsaturated market.... Our idea was the solution. We didn't explore the problem more" (emphasis added). Similarly, a team member of Luete noted, "I've always found our product sexy, and that hasn't changed.... When the business guys wanted to take business plan sessions, I always said, 'We first have to prove that this works'." Thus, in attempts to engage members of their communities of inquiry, the unsuccessful entrepreneurial teams focused on addressing opportunity aspects they knew were problematic rather than focusing on accessing information about opportunity aspects that were unexpected yet potentially problematic.

Therefore, given their generalist composition, the unsuccessful entrepreneurial teams took a focused approach to engaging with their communities of inquiry. Focused community engagement refers to when entrepreneurial teams interact with their communities of inquiry to explore specific aspects of their potential opportunity they know they want to address and not to generate information entirely new to them. Over time, this type of engagement leads to highly incremental changes to opportunities.

\section{Interacting with a Community of Inquiry for Opportunity Development}

In our study (Shepherd et al., 2020), we found that the teams' ability to learn from their communities of inquiry for opportunity development depended on how they engaged with their communities of inquiry in gathering information, generating alternatives, and testing conjectures. Gathering information refers to investing time and other resources into exploring and collecting data about a potential opportunity. Generating alternatives refers to using novel insights from information-gathering efforts to formulate different action courses for consideration when developing a potential opportunity. Testing conjectures refers to using gathered information to assess the validity of a team's propositions that exploiting a potential focal opportunity is both desirable and feasible. Over time, the teams refined their beliefs about the nature of their potential opportunities. The successful entrepreneurial teams that more openly engaged with their communities of inquiry differed in these three activities from the unsuccessful entrepreneurial teams that had more focused engagement with their communities of inquiry. 


\section{Open Community Engagement and Gathering Diverse Information}

The entrepreneurial teams that openly engaged with their communities of inquiry gathered new information about their potential opportunities from a wide range of community members. This open-engagement approach also led these entrepreneurial teams to add new groups to their communities of inquiry (i.e., the communities expanded and became more diverse). This new information from community members informed the teams' changes to their potential opportunities. For example, Perahta interacted with several "distributors who know the market and might be able to point out problems or optimization potentials." Similarly, both Philipinna and Perahta used their professional networks to access potential customers to generate information useful in opportunity development. However, these entrepreneurial teams also purposefully expanded beyond their current networks to increase the size and diversity of their communities of inquiry by, for example, adding potential customers and experts with whom they had no previous relationships. Adding new stakeholders to their communities of inquiry opened these entrepreneurial teams to new information about their potential opportunities. This new information included unexpected (based on team members' current knowledge) information useful for opportunity development.

From early in the opportunity-development process, these successful entrepreneurial teams used rudimentary prototypes to generate more information from their interactions with their communities of inquiry. Presenting prototypes to community members enabled the teams to "see" people's reactions to the current conceptualizations of their potential opportunities. In particular, potential customers provided critical feedback, but so did other community members. For example, Penn showed an early prototype to potential customers while acknowledging that it "looked extremely ugly at that point." Indeed, the team's mentor complimented them on their "level of proactivity in seeking out advice from different types of people, proving their high levels of self-reflection." The founders of Perahta also described their motivation for interacting with their community of inquiry as "repeatedly acquiring as much information from [the] target group as possible in short amounts of time." Indeed, the Philipinna founders emphasized "always showing the prototype or parts of it to get people hooked on the product." In each of these examples, the communities of inquiry reciprocated the teams' ongoing efforts to engage in conversation. Drawing on prototypes, the successful entrepreneurial teams benefited from systematic and continuous dialogue 
with their community members, including potential customers, experts, coaches, and mentors. As a result, these teams expanded their webs of relationships to gather information about their potential opportunities and generate new knowledge to refine their potential opportunities.

\section{Focused Community Engagement and Gathering Specific Information}

The teams relying on focused engagement with their communities of inquiry (i.e., the unsuccessful entrepreneurial teams) directed their efforts toward engaging technical and market experts to resolve specific issues that had emerged during opportunity development. Thus, their interactions were primarily with small and specialized audiences within larger potential communities of inquiry. In contrast to the successful entrepreneurial teams, these entrepreneurial teams had few interactions with potential customers and thus did not acquire or integrate much information from these important members of their communities of inquiry. These teams seemed to engage in focused engagement with their communities of inquiry for several reasons. First, the team members lacked specialized expertise in various topics, so they were concerned that interacting with a broad range of community members would result in information that was inconsistent with their beliefs and desires about their technologies and target markets. For example, one of Ludwig's founders told us the following:

We don't want to annoy them and waste everybody's time because ... you need to have some results from technical prototype tests. That's why you better focus on the technical development, and then hopefully you'll receive the right results from the tests. Then you can then use that to make progress on the market side. And those results will also make you much more convinced about what to believe about all of this.

Furthermore, Lamar's coach expressed the belief that "the team didn't quite have the courage to step up to [interact with] their customers."

Second, when these unsuccessful teams did interact with members of their communities of inquiry who could provide new and unexpected information, they often did so because they felt they should, not because they wanted to acquire and learn from such information. As a result, these teams had few interactions with community members they believed were too distant from their current knowledge, potential opportunities, 
and envisioned opportunities. For example, when these teams' engaged community members, they did so in a relatively superficial and abstract way (because they did not display prototypes). The interactions were also unidirectional; the teams failed to develop effective dialogue with community members (i.e., they did not engage in back-and-forth exchanges with community members). One potential customer described his interaction with Lamar after participating in the team's pilot study (which took place over a year into opportunity development): "I sent the team five pages full of feedback about three weeks ago, and they haven't gotten back to me on those points, apart from thanking me for taking part. So, I don't know what's going to happen now. I've stopped testing."

Finally, the unsuccessful entrepreneurial teams shared the conviction that "by no means should you ever show an unfinished product to potential customers" (one of Lorah's founders) or to other members of their communities of inquiry. As a result, they only presented prototypes to their communities of inquiry when they felt sufficiently confident about the prototypes' appearance, capabilities, and performance. That is, in the early stages of opportunity development, the teams' lack of confidence in their prototypes' technological performance and appearance obstructed them from seeking feedback on prototypes. Only late in opportunity development did the teams started to show rather "polished" prototypes to selected members of their communities of inquiry and, specifically, to potential customers.

Therefore, the successful entrepreneurial teams openly engaged with their communities of inquiry to gather diverse information to facilitate opportunity development. Furthermore, they expanded the size and diversity of their communities of inquiry through weak ties. They presented rudimentary prototypes early to engage in a dialogue with community members, especially potential customers. In contrast, the unsuccessful entrepreneurial teams focused their engagement with communities of inquiry to gather specific information for opportunity development. They engaged narrow communities of experts and others who could provide technical and market information, and they developed sophisticated prototypes before using them to interact with community members. Because these prototypes were already sophisticated and were only presented to the communities of inquiry late in the process, the feedback from these interactions was limited and had little impact on opportunity development. 


\section{Open Community Engagement and Generating Multiple Alternatives}

After the successful entrepreneurial teams openly engaged with their communities of inquiry to gather new information, they explored multiple alternatives for improving the current state of their potential opportunities. These interactions allowed them to take the community members' perspectives when thinking about their potential opportunities, as one of Peppi's founders explained:

We would always recommend asking from a problem perspective and going into interviews with an open mind. I mean, in the beginning, I always let them tell me whatever came to their mind about how they manage their daily information and knowledge management and how they collaborate as a team. And then it figuratively gushes out of them, and I try to write down as much as I can.

For these interactions to be effective, it was important for the entrepreneurial teams to withhold their own ideas for opportunity development to avoid priming community members toward the current approach and to ensure that all team members kept an open mind.

Engaging members of their communities of inquiry with prototypes of their potential opportunities early in the opportunity-development process (before even determining which functions these prototypes should entail) facilitated the joint exploration of solution alternatives between the entrepreneurial teams and various community members. For example, Peppi systematically gathered data at the beginning of opportunity development, carrying out surveys with many potential customers to explore the potential problems customers would experience and possible solutions to those problems. After the team members agreed upon a possible solution to a problem, they quickly presented a rudimentary prototype to explore potential customers' interest in buying a finished version of the product in the future. After interacting with potential customers, the Peppi team soon realized that "it would fail due to students' lack of willingness to pay for non-recreational services" (one of Peppi's founders). The team members came up with alternative features for their potential opportunity, a second solution involving a different customer group, and a different set of services. Still, they discarded 
these alternatives based on feedback from experts and mentors in their community of inquiry. Ultimately, the team identified a third unexpected solution. This solution arose from a discussion with a potential customer group that had the highest buying power.

\section{Focused Community Engagement and Generating Related Alternatives}

Based on their information-gathering efforts, the unsuccessful entrepreneurial teams relied on a small set of members of their communities of inquiry with whom they could explore alternative solutions to particular development issues. They did not explore multiple alternative markets or different technology-market combinations. For example, considering how to protect their digital product from power outages, the Lamar team generated two alternative solutions. As one founder explained, this "seemingly small technicality [was] hugely important because it affects many parts of the whole concept." Both solutions offered advantages and came at similar costs, yet Lamar's team members prioritized the solution's features differently, so the team found it "difficult to come to a decision rationally" (one of Lamar' founders). However, rather than solving this issue by engaging with a broad range of community members, such as potential customers or distributors, the team redoubled its exploration of possible technological angles. These narrow efforts to resolve the issue caused the team to repeatedly engage the same set of technical experts. Thus, more and more time was "spent... discussing all the alternatives, going back and forth" (one of Lamar's founders). As this example illustrates, these unsuccessful entrepreneurial teams had few interactions with more diverse community members about different market alternatives to develop their potential opportunities.

Therefore, the successful entrepreneurial teams that openly engaged with their communities of inquiry generated many and varied ideas over time to improve their potential opportunities. In particular, they sought and relied heavily on users' perspectives to inform opportunity development. In contrast, the unsuccessful entrepreneurial teams using focused engagement with their communities of inquiry generated few ideas over time and often relied on experts' perspectives. 


\section{Open Community Engagement and Disconfirming Opportunity}

\section{Conjectures}

The successful entrepreneurial teams that openly engaged with their communities of inquiry tested their opportunity conjectures by interacting with community members in a manner that would induce unexpected information (including negative feedback). Identifying unexpected information about their potential opportunities (e.g., current prototypes) early in the development process allowed these teams to make changes to their potential opportunities and increase the likelihood of new venture progress and success. For example, after interacting with potential customers over rudimentary prototypes, these teams sought indepth feedback on unsatisfactory or unnecessary technological features of the proposed products and other potential problems with the prototypes. These efforts revealed unexpected information about the potential opportunities that the teams valued and learned from. A founder of Penn reflected this approach to using the venture's prototype:

Once it's being used every day, you can see if it really stands the test. Whether it's effective or whether there's too much discharge ... maybe the membranes snatch every five hours. We've already tested it ourselves, but you never know how it's going to be in real life: maybe patients stick their fingers into it or a spoon. Can you apply this concept in a clinic at all? That'll be exciting to find out.

However, over and above the desire to generate unexpected information about their potential opportunities, these successful teams sought and acquired both positive and negative feedback. For example, when conversations with community members were perceived as "uncomfortable because things come up that you wanted to suppress," the team members reminded themselves that "it's good that these things come up anyway" (one of Philipinna's founders). The teams pushed themselves to withhold their expectations to keep an open mind to the feedback generated from interactions with their communities of inquiry. Indeed, based on the unexpected information received from their communities of inquiry, these successful entrepreneurial teams developed their opportunities by analyzing the results of tests of their opportunity conjectures in an open-minded way. For example, a founder of Philipinna described the team's approach as follows: 
The "idea fit" is there when people pat you on the back and say, "Great idea, we want to try that." But when you notice that you can't actually manage to sell it, then you don't have a "product fit." You can only find that out when you build prototypes, give them to customers to play with and get a feeling for it, and then either systematically optimize certain features or kick them.

Beyond seeking feedback to generate unexpected information about their potential opportunities, the successful entrepreneurial teams observed customers as they used the prototypes. They paid particular attention to potential customers' unexpected behaviors to identify issues that the customers may have been unaware of and unable to verbalize. For example, one of Peppi's founders described this approach as follows:

You try to read their initial reactions and just write them down without filtering anything. And you observe how they handle the product even if they're not saying anything. Like if someone takes ages to find a button, then you absolutely need to make a note of that. That's negative feedback in a way, but it's super important to do this.

Once these successful teams had gathered sufficient information, they adapted their opportunities to accommodate this new and unexpected information.

Overall, these successful entrepreneurial teams openly engaged with their communities of inquiry to generate new, unexpected information. This new, unexpected information guided the entrepreneurial teams to various community members, and the teams approached these external information sources with an open mind to inform opportunity development. Due to this open-engagement approach, these entrepreneurial teams could make fundamental and radical adaptations to their opportunities' technological and business-related aspects. Overall, these entrepreneurial teams enacted learning efforts early and often in the opportunity-development process.

\section{Focused Community Engagement and Confirming Opportunity Conjectures}

When the unsuccessful entrepreneurial teams interacted with members of their communities of inquiry to collect information, they sought feedback that they expected (given their current development paths) to be important for improving their potential opportunities. Although this feedback 
seeking may have generated important information and led to incremental refinements of their opportunities, it did not generate information beyond the teams' expectations; that is, their feedback-seeing efforts did not generate unexpected information about their potential opportunities. For example, when observing Ludwig's multiple presentations of their potential opportunity to technical experts, we noticed a strong emphasis on the envisioned solution's projected technological benefits. However, as one of the founders noted, "We kind of always just automatically put a label on it-'reduces noise'-without actually knowing if it will end up working that way [laughs]. But in theory, we'll filter out all these effects, so our product should be quieter." In presenting their solutions, these teams did not test their opportunity conjectures. For example, they did not offer prototypes during the early stage of opportunity development to determine potential customers' reactions. Instead, these teams initially evaluated prototypes strictly within their ventures' boundaries.

Only when the prototypes were well established and "polished" did the teams show them to outsiders, but they only interacted with a small set of potential customers. They focused on obtaining feedback about their prototypes within the narrow constraints of the teams' expectations about the nature of their potential opportunities. For example, one of Lorah's founders remarked, "She [a potential customer] said she likes it. She was using it in a weird way. To be honest, we didn't really understand why. We did ask her, but it still didn't really make sense to us afterward." When we later interviewed this potential customer, it turned out that she found the prototype interfered with her work habits and stopped using it for the most part. Lorah's team members discounted the negative feedback by describing the potential customer's behavior as "weird." The team attributed blame to the potential customer, not to themselves or their technology, so there was nothing for them to learn and no need to make changes based on information from an "outlier." Indeed, during testing, the user expressed an overall positive evaluation of the product because she did not want to hurt the team's feelings. The team readily accepted the positive superficial feedback while discounting and ignoring the negative feedback from the potential customer's behavior as she tried to use the product. Other community members also found that these teams reacted "defensively" (Lamar customer) to any unexpected or negative feedback about their potential opportunities. Indeed, Lorah's mentor noted, "When I give them more detailed feedback, they go into the mindset of 'We know it better anyway'." The unsuccessful entrepreneurial 
teams decided not to act on feedback whenever the suggested solutions or prototypes received ambiguous feedback (i.e., outside the teams' knowledge, expectations, or interests). They perceived such information as tangential to opportunity development. Instead, these entrepreneurial teams attended to feedback (and subsequently returned to issues) related to improving their potential opportunities' existing features and capabilities and ignored or discounted information that signaled the need to replace or add substantially new features and capabilities.

Therefore, the successful entrepreneurial teams openly engaged with their communities of inquiry to generate and use unexpected information about their potential opportunities. To generate such information, they observed many users early in the opportunity-development process. In contrast, the unsuccessful entrepreneurial teams used focused engagement with their communities of inquiry to seek feedback consistent with the current trajectories of their potential opportunities, and they observed few users. Even when their communities of inquiry provided opportunity feedback that was both consistent and inconsistent with expectations, these teams focused on consistent feedback as motivation for further improvements to their potential opportunities and mostly ignored inconsistent feedback (i.e., confirmation bias [Nickerson, 1998]).

\section{A Social Model of Opportunity Development}

Figure 2.1 illustrates our social model of opportunity development (detailed in Shepherd et al., 2020). In the top panel of Fig. 2.1, we illustrate the successful entrepreneurial teams' model-teams composed of varied specialists that openly engaged with their communities of inquiry. During opportunity development, this engagement with their community members involved generating diverse information, multiple alternatives (technology and market) through co-creation, and consistent and inconsistent (vis-à-vis expectations) information to develop their potential opportunities. In the bottom panel, we show the unsuccessful entrepreneurial teams' model-teams composed of generalists that focused their engagement with their communities of inquiry. These teams gathered specific information from experts that they expected would be sufficient for opportunity development, generated few alternatives for developing their potential opportunities, emphasized feedback suggesting that their potential opportunities were on the "right" development path, 


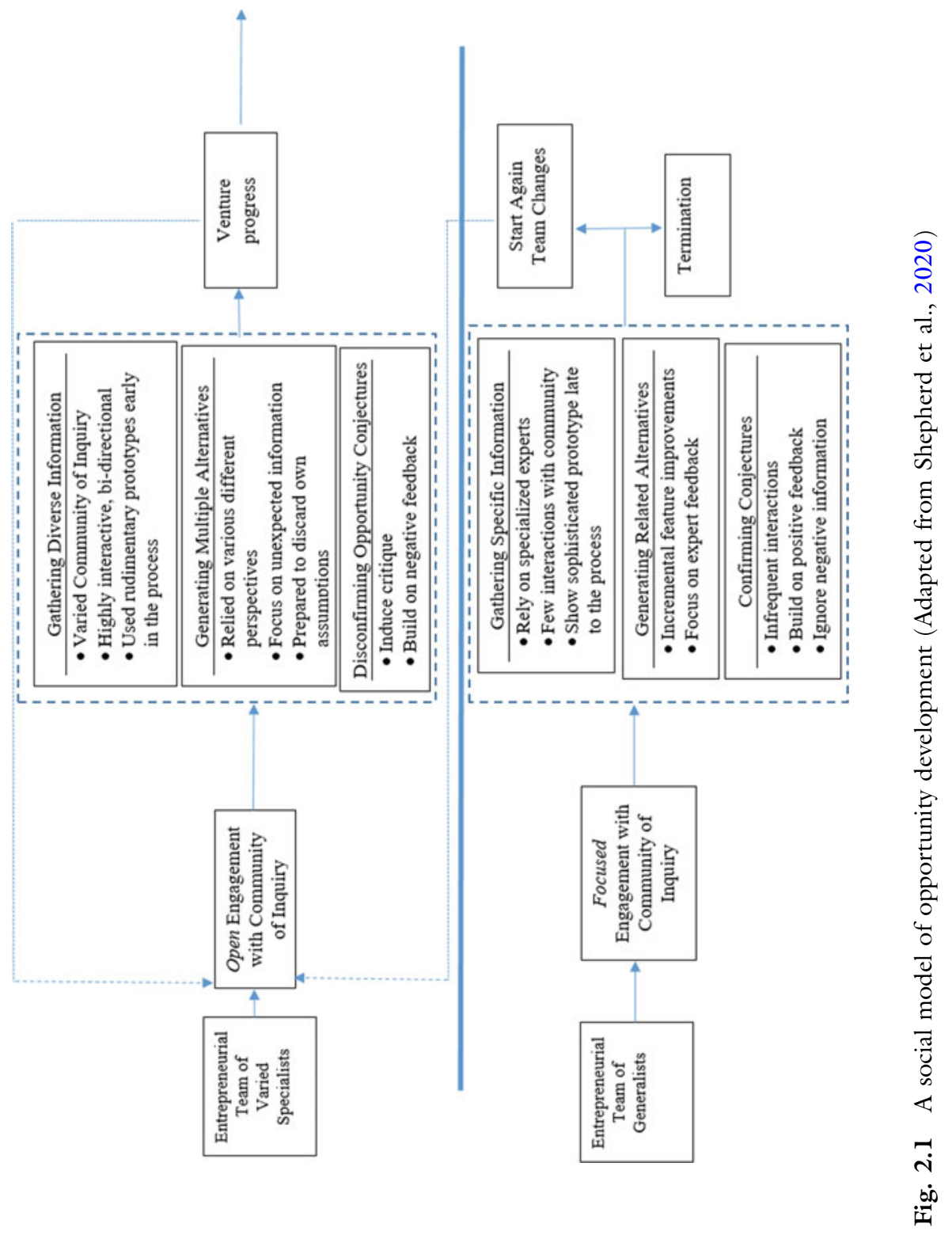


and discounted or ignored information suggesting they needed to make major changes.

This chapter explained how access to resources is necessary but not sufficient for progress in opportunity development. Some of the teams we studied made more of their communities of inquiry by openly engaging them in the opportunity-development process. These teams iterated dynamically during opportunity development. In contrast, the unsuccessful teams gathered specific information from experts who they expected to be important in opportunity development, generated few alternatives, and tested opportunity conjectures by seeking confirmation. These teams' focused engagement with their communities of inquiry led to little opportunity development and, ultimately, to either a major pivot away from the focal team's initial potential opportunity or the termination of the entrepreneurial endeavor altogether.

This chapter explained how entrepreneurial teams engage communities of inquiry for opportunity development and, ultimately, venture progress. The social model of opportunity development highlights how an entrepreneurial team's knowledge influences their approach to engaging with its community of inquiry for opportunity development. In doing so, the model makes important contributions to the literature on opportunity development and, specifically, to research on social learning in the entrepreneurial context. Although there is considerable research on recognizing fully formed opportunities, there is also research (mostly conceptual and philosophical) on the co-construction of opportunities. The model described in this chapter offers new insights into opportunity development's social process of co-construction.

The social model of opportunity development (Shepherd et al., 2020) described in this chapter offers three primary theoretical implications. First, research on the development of opportunities explains the social aspects of such development in terms of networks, social capital, and interactions with communities of inquiry (Hoang \& Antoncic, 2003; Seyb et al., 2019). The current model extends this research stream by offering new insights into how entrepreneurial teams differ in their engagement with their communities of inquiry and how these differences impact opportunity development. The successful entrepreneurial teams we studied (i.e., those whose ventures were progressing well) openly engaged with their communities of inquiry for opportunity development, whereas the unsuccessful entrepreneurial teams relied on focused engagement. The successful entrepreneurial teams also differed from 
the unsuccessful teams in the timing of their specific actions (e.g., showing prototypes to community members early vs. late), their information collection (diverse vs. specific), and their generation of alternatives (multiple vs. related) with community members.

Second, research on the process of constructing opportunities has highlighted the uncertainty surrounding potential opportunities and the importance of both information processing and action (Sarasvathy, 2001; Wood \& McKinley, 2010) for learning to develop potential opportunities. However, there has been little exploration of how and what information entrepreneurs use for opportunity development, what actions entrepreneurs take to engage others in the opportunity-development process, and why entrepreneurial teams differ in the benefits they derive from social interactions when developing opportunities. While founders' prior knowledge explains learning in new domains (Corbett, 2007; Grégoire et al., 2010), there are limits to using prior knowledge to direct activities in uncertain environments. Although the successful teams relied on their members' prior knowledge, these teams still openly engaged with their communities of inquiry to generate and use new information. This open engagement reflects a reluctance to rely solely on prior knowledge. It demonstrates the importance of unexpected information (vis-à-vis the founders' shared knowledge structures [see Chapter l]) for opportunity development. Therefore, while relying on prior knowledge can lead to cognitive blindness (Tripsas, 2009; Tripsas \& Gavetti, 2000), entrepreneurial teams can avoid (or minimize) this cognitive blindness by openly engaging their communities of inquiry in the opportunitydevelopment process. Thus, this model extends theorizing on the role of prior knowledge in opportunity development by revealing a "social" way whereby prior knowledge guides opportunity development while minimizing cognitive blindness-namely, through influencing the use of various means of engaging communities of inquiry.

Finally, it seems obvious to highlight the importance of collecting information on the potential markets and technologies for a potential opportunity before fully exploiting it (e.g., Choi \& Shepherd, 2004; Hmieleski \& Baron, 2008). Indeed, as we described in this chapter, the social model of opportunity development provides new theoretical insights into the role of a community of inquiry and the different mechanisms for engaging community members. Linked to differences in how founders engage with their communities of inquiry, we highlighted how entrepreneurial teams differ in gathering information (i.e., diverse 
or specific), generating alternatives (multiple or related), and testing opportunity conjectures (disconfirmation or conformation). These differences in social learning influence opportunity development. Specifically, entrepreneurial teams lack progress when they use a focused-engagement approach, gather information from a narrow group of community-ofinquiry members, generate a limited set of incremental alternatives, and use information consistent with their prior opportunity beliefs. This chapter makes explicit the critical factors that explain how entrepreneurs can effectively engage their communities of inquiry (as well as the mechanisms of engaging communities of inquiry that are likely to lead to limited opportunity development and unsuccessful venture performance).

Based on the social model of opportunity development, we tentatively offer the following practical advice to potential founders: First, create teams of members with various specialist knowledge domains. Second, openly engage a community of inquiry to gather diverse information by maintaining an open mind when interacting with the broad and diverse community of inquiry, including displaying prototypes early. Third, co-create multiple alternatives with many community members to reveal and learn from unexpected information about the potential opportunity. Finally, seek to disconfirm opportunity conjectures by inducing critique from the community of inquiry and avoid ignoring or discounting information that fails to confirm their opportunity conjectures.

\section{CONCLUSION}

This chapter explained a social model of opportunity development (Shepherd et al., 2020). The model proposes that successful entrepreneurial teams consist of varied specialists who openly engage their communities of inquiry. By openly engaging communities of inquiry, entrepreneurial teams can gather diverse information, generate multiple alternatives, and test conjectures about their potential opportunities through disconfirmation. In contrast, unsuccessful entrepreneurial teams consist of generalists who rely on focused engagement with their communities of inquiry. Focused engagement leads these teams to gather specific and expected information from experts in narrow domains, generate few alternatives, and test opportunity conjectures by seeking and using information that confirms these conjectures. This social model offers new insights into entrepreneurial teams' engagement with their communities of inquiry for opportunity development and, ultimately, new venture progress. 


\section{REFERENCES}

Alvarez, S. A., Young, S. L., \& Woolley, J. L. (2015). Opportunities and institutions: A co-creation story of the king crab industry. Journal of Business Venturing, 30(1), 95-112.

Autio, E., Dahlander, L., \& Frederiksen, L. (2013). Information exposure, opportunity evaluation, and entrepreneurial action: An investigation of an online user community. Academy of Management Journal, 56(5), 1348-1371.

Choi, Y. R., \& Shepherd, D. A. (2004). Entrepreneurs' decisions to exploit opportunities. Journal of Management, 30(3), 377-395.

Corbett, A. C. (2007). Learning asymmetries and the discovery of entrepreneurial opportunities. Journal of Business Venturing, 22(1), 97-118.

De Carolis, D. M., \& Saparito, P. (2006). Social capital, cognition, and entrepreneurial opportunities: A theoretical framework. Entrepreneurship Theory and Practice, 30(1), 41-56.

Dencker, J. C., Gruber, M., \& Shah, S. K. (2009). Pre-entry knowledge, learning, and the survival of new firms. Organization Science, 20(3), 516-537.

Dosi, G. (1982). Technological paradigms and technological trajectories. Research Policy, 2(3), I47-162.

Eckhardt, J. T., \& Shane, S. A. (2003). Opportunities and entrepreneurship. Journal of Management, 29(3), 333-349.

Grégoire, D. A., Barr, P. S., \& Shepherd, D. A. (2010). Cognitive processes of opportunity recognition: The role of structural alignment. Organization Science, 21(2), 413-431.

Greve, A., \& Salaff, J. W. (2003). Social networks and entrepreneurship. Entrepreneurship Theory and Practice, 28(1), 1-22.

Hmieleski, K. M., \& Baron, R. A. (2008). Regulatory focus and new venture performance: A study of entrepreneurial opportunity exploitation under conditions of risk versus uncertainty. Strategic Entrepreneurship Journal, 2(4), 285-299.

Hoang, H., \& Antoncic, B. (2003). Network-based research in entrepreneurship: A critical review. Journal of Business Venturing, 18(2), 165-187.

Kazanjian, R. K. (1988). Relation of dominant problems to stages of growth in technology-based new ventures. Academy of Management Journal, 31(2), 257-279.

McFadyen, M. A., \& Cannella, A. A. (2004). Social capital and knowledge creation: Diminishing returns of the number and strength of exchange relationships. Academy of Management Journal, 47(5), 735-746.

Nickerson, R. S. (1998). Confirmation bias: A ubiquitous phenomenon in many guises. Review of General Psychology, 2(2), 175-220.

Sarasvathy, S. D. (2001). Causation and effectuation: Toward a theoretical shift from economic inevitability to entrepreneurial contingency. Academy of Management Review, 26(2), 243-263. 
Seyb, S. K., Shepherd, D. A., \& Williams, T. A. (2019). Exoskeletons, entrepreneurs, and communities: A model of co-constructing a potential opportunity. Journal of Business Venturing, 34(6), 105947.

Shepherd, D. A. (2015). Party on! A call for entrepreneurship research that is more interactive, activity based, cognitively hot, compassionate, and prosocial. Journal of Business Venturing, 30(4), 489-507.

Shepherd, D. A., Sattari, R., \& Patzelt, H. (2020). A social model of opportunity development: Building and engaging communities of inquiry. Journal of Business Venturing, 106033.

Tripsas, M. (2009). Technology, identity, and inertia through the lens of "The Digital Photography Company." Organization Science, 20(2), 441-460.

Tripsas, M., \& Gavetti, G. (2000). Capabilities, cognition, and inertia: Evidence from digital imaging. Strategic Management Journal, 21(10/11), 1147-1161.

Wood, M. S., McKelvie, A., \& Haynie, J. M. (2014). Making it personal: Opportunity individuation and the shaping of opportunity beliefs. Journal of Business Venturing, 29(2), 252-272.

Wood, M. S., \& McKinley, W. (2010). The production of entrepreneurial opportunity: A constructivist perspective. Strategic Entrepreneurship Journal, 4(1), 66-84.

Open Access This chapter is licensed under the terms of the Creative Commons Attribution 4.0 International License (http://creativecommons.org/licenses/ by $/ 4.0 /$ ), which permits use, sharing, adaptation, distribution and reproduction in any medium or format, as long as you give appropriate credit to the original author(s) and the source, provide a link to the Creative Commons license and indicate if changes were made.

The images or other third party material in this chapter are included in the chapter's Creative Commons license, unless indicated otherwise in a credit line to the material. If material is not included in the chapter's Creative Commons license and your intended use is not permitted by statutory regulation or exceeds the permitted use, you will need to obtain permission directly from the copyright holder.

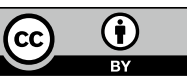

